THE WORKWEEK OF CAPITAL AND ITS CYCLICAL IMPLICATIONS

\author{
Finn E. KYDLAND* \\ Carnegie-Melion University \\ Pittsburgh, PA 15213, USA \\ Edward C. PRESCOTT* \\ Federal Reserve Bank of Minneapolis \\ and University of Minnesota \\ Minneapolis, MN 55455, USA
}

\begin{abstract}
$\underline{\text { ABSTRACT }}$
The neoclassical growth model studied in Kydland and Prescott [1982] is modified to permit the capital utilization rate to vary. The effect of this modification is to increase the amplitude of the aggregate fluctuations predicted by theory as the equilibrium response to technological shocks. If, following Solow [1957], the changes in output not account for by changes in the labor and tangible-capital inputs are interpreted as being the technology shocks, the statistical properties of the fluctuations in the post-war United States economy are close in magnitude and nature to those predicted by theory.
\end{abstract}

Running Title: The Workweek of Capital

Send Galley Proofs to:

Edward C. Prescott Research Department

Federal Reserve Bank of Minneapolis

250 Marquette Avenue

Minneapolis, Minnesota 55480 
I. Introduction

In Kydland and Prescott [1982], the competitive neoclassical growth model with shocks to technology is studied. Leisure was introduced as an additional argument affecting preferences and labor services as an input to the aggregate production function. This artificial economy was calibrated so that its equilibrium would display the growth observations of Kuznets [1966]. In particular, its average consumption and investment shares of output match those of the post-war U.S. economy as do the capital-output ratios and factor shares. Further, the allocation of time between market and nonmarket production activities is consistent with household studies and does not change secularly as technology advances.

Services from inventory stocks were introduced as a factor of production and a production period for new capital consistent with micro observations assumed. We found that the competitive equilibrium for this economy displays fluctuation in output having amplitude and serial correlation properties similar to those of the U.S. economy. The relative variability of both consumption and investment matched the data. Further, the majority of the variability in output was accounted for by variability in the labor input. This exercise lead us to the conclusion that if, following Solow [1957], residuals in the aggregate production function are interpreted as shocks to technology, there would be a puzzle if industrial market economies did not display business cycle fluctuations. 
For both the neoclassical growth model and post-war American economies capital stocks do not fluctuate with output. At the business cycle frequencies these variables are nearly orthogonal. But, the services of capital need not be equal to the capital stock as for the model that we studied. The utilization of capital can and surely does fluctuate systematically with output and employment. A factory can be operated two shifts rather than one or operated six rather than five days a week. If hours of labor services are proportionate to the workweek of capital, increases in labor services do not reduce the ratio of capital services to labor services.

The question that is addressed in this paper is how does the nature of the fluctuations predicted by the stochastic growth model change if the workweek of capital is permitted to vary? The principal finding is that fluctuations are larger and the stochastic growth model better mimics the behavior of the American economy .

In Section II, the economy that we study is specified. In Section III, we show that by defining workdays of different lengths to be different commodities, the economy can be put into the Debreu [1954] general equilibrium framework. The competitive equilibrium is found by supporting the Pareto optimum. The model is calibrated in section IV and findings are reported in section V. Section VI contains a concluding comment. 


\section{The Economy}

\section{Preferences}

The stand-in household's preferences are ordered by

$$
E \sum_{t=0}^{\infty} \beta^{t} u\left(c_{t}, \sum_{i=0}^{\infty} \alpha_{i} e_{t-i}\right)
$$

where $c_{t} \geq 0$ is date $t$ consumption, $l_{t} \geq 0$ date $t$ leisure, $0<B$ $<1$ is the discount factor, and $E$ the expectation operator. The parameters $\alpha_{i}$ are constrained to sum to 1 and $\alpha_{i+1} / \alpha_{i}=1-n$ for $i$ $=1,2, \ldots$. Thus, $0<\alpha_{0} \leq 1$ and $0 \leq n \leq 1$ determine the values of the $\alpha_{i}$. The case of $\alpha_{0}=1$ corresponds to a standard timeseparable utility function. Theoretically, of course, $\alpha_{0}$ could be greater than one, implying that leisure in neighboring periods are complements rather than substitutes. Justifications for so restricting $\alpha_{0}$ to be less than one and for this distributed lag of leisure based upon household production theory with household capital can be found in Kydland [1983] and evidence based on panel data in Hotz, Kydland and Sedlacek [1985].

The period utility function is assumed to have the form

$$
u\left(c_{t}, \alpha(L) e_{t}\right)=\left[c_{t}{ }^{\mu}\left(\alpha(L) e_{t}\right)^{1-\mu}\right]^{\gamma / \gamma}
$$

where $\gamma<1$ and $\gamma \neq 0$. To summarize, $B, \alpha_{0}, \eta, \gamma$ and $\mu$ are the parameters of preferences. The unit elasticity of substitution between $c_{t}$ and $\alpha(L) l_{t}$ was dictated by the requirement that there be no secular change in $\alpha(L) l_{t}$ associated with secular increase in productivity. The household endowment of time per period is normalized to be one.

The utility function can also be represented as follows: 


$$
u\left(c_{t}, \alpha(L) e_{t}\right)=u\left(c_{t}, \alpha_{0} e_{t}+\eta\left(1-\alpha_{0}\right) a_{t}\right)
$$

where

$$
a_{t+1}=(1-\eta) a_{t}+e_{t}
$$

This alternative formulation permits the application of recursive methods.

Technology

Aggregate output is constrained by

$$
f\left(z_{t}, h_{t}, k_{t}, y_{t}\right)=\left[\left(z_{t} h_{t}^{\psi} k_{t}^{\theta}\right)^{-v}+\sigma y_{t}^{-v}\right]^{-1 / v}
$$

where $k_{t}$ is the productive stock of physical capital other than inventories, $y_{t}$ the stock of inventories, and $z_{t}$ the date $t$ technology shock. Restrictions on the parameters are $0<\theta<1, \sigma\rangle$ $0, \nu>-1$, and $1-\theta\langle\psi<1$. Because $\psi+\theta>1$, there are apparent increasing returns. With $\psi=1-\theta$, the only margin over which hours can be varied is the number of workers operating a given quantity of capital. With $\psi=1$, the only margin is the length of the workday of capital and labor.

We think this captures in a reasonable way the option to vary the capital utilization rate. One way to increase output is to operate a given plant more hours per week, say by operating it six rather than five days per week or two racher than one shift per day. Another way is to put into operation a marginal plant or machine. Such adjustments on average are probably associated with some decrease in the instantaneous capital-output ratio as variations in output are typically born by the less capital inten- 
sive plants. The third margin is to increase the number of workers per plant. Ex post substitution opportunities are surely smaller than ex ante opportunities but they are not zero. These considerations are what led us to select this technology.

The production function differs from the one we used previously in another important respect. For the above CES production function, capital and labor are combined to form a composite input and that composite input combined with inventories to produce goods and services. Previously, $k_{t}$ and $y_{t}$ were nested together to form a composite capital service which in turn was combined with the labor input to produce output. We think these assumptions made here match better with micro observations. They also result in inventories being a procyclical variable, rather than moving countercyclically, in conformity with observations.

Total output is allocated to noninventory investment $i_{t}$, inventory investment $y_{t+1}-y_{t}$, and consumption $c_{t}$ :

$$
i_{t}+c_{t}+y_{t+1}-y_{t} \leq f\left(z_{t}, h_{t}, k_{t}, y_{t}\right) \text {. }
$$

New productive capacity is not built in a period, which we take to be a quarter of a year. The construction period is $\mathrm{J}$ quarters, with $\phi_{J+1-j}$ being the fraction of the value put in place in the $j^{\text {th }}$ period of construction for $j=1, \ldots, J$. Let $s_{j}$ for $j=$ $1, \ldots, \mathrm{J}$ be the total value of projects (that is, the sum of value put into place at each of the $j$ stages) that are $j$ periods from completion. Then,

$$
i_{t}=\sum_{j=1}^{J} \phi_{j} s_{j t} .
$$


Note that the $\phi_{j}$ sum to one and are positive as they are fractions.

The capital stocks that index the effect of past production decisions upon subsequent production possibilities are $\mathbf{s}_{1}$, $\ldots, \mathrm{s}_{\mathrm{J}-1}, \mathrm{k}_{\mathrm{t}}$ and $\mathrm{y}_{\mathrm{t}}$. Productive capital is assumed to depreciate geometrically at rate $0<\delta<1$ so

$$
k_{t+1}=(1-\delta) k_{t}+s_{1 t} .
$$

Further,

$$
s_{j, t+1}=s_{j+1, t}
$$

for $j=1, \ldots, J-1$. The latter set of constraints is that projects $j+1$ stages from completion are $j$ stages from completion next period.

The shock to technology $z_{t}$ is the sum of a persistent component $\mathrm{z}_{1 \mathrm{t}}$ and a transitory component $\mathrm{z}_{2 t}$

$$
z_{t}=z_{1 t}+z_{2 t}+\bar{z}
$$

The process on $z_{1 t}$ is first-order autoregressive with

$$
z_{1, t+1}=\rho z_{1 t}+\xi_{1, t+1} \quad 0<\rho<1
$$

while

$$
z_{2, t+1}=\xi_{2, t+1} .
$$

Further $z_{t}$ is observed only with error at the beginning of the period. Observed is

$$
\pi_{t}=z_{t}+\xi_{3 t} .
$$


Decisions on employment $h_{t}$ and new capital projects $s_{j t}$ are made contingent on $\pi_{t}$ and the previous history of the $z_{t}$. Output is then observed and $z_{t}$ deduced. Then the consumptioninventory carry-over decision is made contingent upon $z_{t}$ as well as the history of shocks. The vectors $\xi_{t}$ are iid normal with mean zero and diagonal covariance. With this assumption, the conditional expectations of $z_{1 t}$ and $z_{2 t}$ based upon available information are sufficient, relative to the history, for decision making. Further, the conditional expectations are linear functions of their previous value and the latest observation whether it be $\pi_{t}$ or $z_{t}$. For further details, see Kydland and Prescott [1982].

III. Supporting the Pareto Optimum as a Competitive Equilibrium The technology appears to display increasing returns to scale and does, if the obvious commodity point is employed--namely, the one for which hours and capital are inputs. Because competitive equilibria fail to exist with increasing returns, an alternative commodity point is needed if we are to use competitive analysis. Our approach is to assume that capital is specific to the household, that is, only the worker can effectively operate his equipment. Then we treat hours-capital pairs as being different commodities. A commodity of type $(k, h)$ provides

$$
\mathrm{zh}^{\psi} \mathrm{k}^{\theta}
$$

units of a composite input. As there are a continuum of commodities, measures are needed to specify the quantities of all these different commodities. See Mas-Colell [1975] and Jones [1984] for competitive theory with measures as commodity points. 
The use of measures permits us to apply competitive equilibrium theory to the study of this economy. A person who works $h$ hours utilizing $k$ units of capital is a type $(h, k)$ worker. Measure $m(A)$ specifies the measure (number) of type $(h, k)$ workers in the measurable set A. The output of the economy at date $t$ is

$$
\left[\left(z \int h^{\psi} k^{\theta} d m\right)^{-v}+\sigma y^{-v}\right]^{-1 / v}
$$

If the set of possible values $(h, k)$ pairs is discrete, output is

$$
\left[\left(z \sum_{h} \sum_{k} h^{\psi} k^{\theta} m_{h k}\right)^{-v}+\sigma y^{-v}\right]^{-1 / v}
$$

where $m_{h k}$ is the number of people who work $h$ hours using $k$ units of capital. This is a constant returns to scale production function with inputs the $\mathrm{m}_{h k}$ and $\mathrm{y}$. This result does not depend upon the set of possible $(h, k)$ pairs being finite.

Let $x=(k, s, y, a)$ denote the vector of the state variables affected by the decisions of agents. Let $R\left(x_{t}, x_{t+1}, z_{t}\right)$ be the maximal obtainable current utility given the technology constraints. This entails maximizing $u\left(c_{t}, \alpha_{0} l_{t}+n\left(1-\alpha_{0}\right) a_{t}\right)$ over measures $m$ with the property that their total mass is one and they place mass upon a single point $(h, k)$. Note $h=1-l_{t}$ and $k \leq k_{t}$. In other words, hours worked is the time endowment less leisure while capital services supplied, k, are constrained by the existing stock of capital.

Let value functions $v_{n}$ be defined recursively as follows:

$$
v_{n+1}(x, z)=\max _{x^{\prime} \in \Gamma(x, z)}\left\{R\left(x, x^{\prime}, z\right)+\beta \int v_{n}\left(x^{\prime}, z^{\prime}\right) \pi\left(z, d z^{\prime}\right)\right\}
$$


given $v_{0}(x, z)=0$. Here $\pi(z, A)$ is the probability $z_{t+1} \in A$ given $z_{t}=z$ and the convex set $\Gamma(x, z)$ specifies the set of feasible $x^{\prime}$ given $\mathrm{x}$ and $\mathrm{z}$. Our computational procedure requires that for each $n$ the maximization problem be concave in $x^{\prime}$ and $v_{n+1}(x, z)$ be concave in $x$. Otherwise, it may not be optimal for the ex ante identical agents to remain identical.

To find the competitive equilibrium allocation, the Pareto optimal allocation which maximizes the average utility of the identical agents is computed. A candidate price system is found from the marginal conditions. As this candidate assigns finite value to all points in the commodity space, it is a valid price system.

IV. Calibrating the Economy and Computing Equilibrium

To determine, for a set of parameter values, the stochastic difference equations describing the equilibrium for this model, we exploit the result that the equilibrium allocation can be found by solving the stand-in utility maximization problem described in the previous sections. The aim is to determine the business cycle variance-covariance properties of the model and to contrast them with data for the post-war U.S. economy. Due to the form of the utility function and the nonlinearity of the resource constraint, this is infeasible for the original formulation of the model. Instead, we study the approximate economy which is found by making a quadratic approximation around the steady state of the exact model. The steady state is also used for the purpose of calibrating the model in the sense of making it consistent with average relations from national income and product accounts and 
with various micro observations. For these reasons, we first turn to the determination of the steady state.

\section{Steady State}

We let variables without time subscripts denote the steady state. It is found by setting $z_{t}$ equal to its unconditional mean, which is denoted by $z$, in every period. The parameter $\mathrm{z}$ is a scale parameter and is chosen so that the steady state output equals one.

The parameters that play a role for the steady state are $\beta, \gamma, \mu, \alpha_{0}$, and $\eta$ from the utility function, and $\delta, z, \theta, \psi, \sigma$, $\phi_{1}, \ldots, \phi_{\mathrm{J}}, \rho$, and $v$, from technology. The variables of the model are consumption $c$, investment plans $s$ which in the steady state are equal to actual investment, inventories y, capital stock $k$, hours $h$, and the real interest rate $r$. For each set of parameter values, a steady state results. Thus, if we denote by $w$ the vector of parameters and let $S$ be the vector of variables, then one can determine a mapping $S(\omega)$.

For our purpose, the inverse mapping is of particular interest, that is, the mappings from part of the vector $S$ or functions thereof to a subset of the parameters. The state vector typically consists of variables for which there are long-run relations in the data that have been essentially constant throughout the sample period. Examples are consumption-output, inventory-output, and capital-output ratios, and households' average allocation of time to market activity.

The steady state interest rate will, in general, have a close relationship to $\beta$ and the rate of growth of consumption. Abstracting from growth, however, we have 


$$
r=(1-\beta) / \beta \text {. }
$$

From the condition $\mathrm{f}_{\mathrm{y}}=\mathrm{r}$ and the fact that steady state output is one, it follows that

$$
\sigma=r y^{v+1} \text {. }
$$

Letting consumption be the numeraire, the steady state relative price of services from capital is $q=(r+\delta) \sum_{j=1}^{J}(1+r)^{j-1} \phi_{j}$. Steady state capital stock then follows from the relation

$$
\theta=q k /\left(1-\sigma y^{-v}\right) \text {, }
$$

where the capital-output ratios are the averages for the post-war U.S. economy. Given the depreciation rate, we have $s=\delta k$. In the steady state, there is no inventory accumulation. Thus, when $\mathrm{s}$ is determined, steady state consumption is total output minus this quantity. We can now also determine from the production function the value of $\mathrm{z}$ that will make steady state output equal one as follows:

$$
z=\left[\left(1-\sigma y^{-v}\right)^{1 / \nu} h^{\psi} k^{\theta}\right]^{-1} .
$$

Turning to the consumer's problem, recall that we already implicitly know $c$, and all that is left to be determined from utility maximization is $h$. Without the dependence of current utility on past leisure choices, its value would have followed from the condition $u_{\ell} / u_{c}=f_{h}$. In the present case, however, the relevant first-order condition can be written as 


$$
\begin{aligned}
& \mu f_{h}^{t} / c_{t}=(1-\mu) \sum_{j=0}^{\infty} \beta^{j} \alpha_{j}\left[\alpha(L) e_{t+j}\right]^{-1} \text { for all } t \text {, where } \\
& f_{h}^{t}=\psi\left(z_{t} k_{t}^{\theta}\right)^{-v} h_{t}^{-\psi v-1} .
\end{aligned}
$$

In the steady state, $c_{t}=c, l_{t}=l$, and $f_{h}^{t}=f_{h}$ for all $t$. Using the facts that $\alpha_{j}$ sum to one, that $\sum_{j=0}^{\infty} \beta^{j} \alpha_{j}=\left(\alpha_{0} r+n\right) /(r+n)$, and that $\ell=1-h$, this expression can be written as

$$
(1-\mu)\left(\alpha_{0} r+n\right) c /(r+n)=(1-h) f_{h} .
$$

\section{Calibration}

The parameters can be divided into two groups, those that affect the steady state vector a great deal, and those which do not. The growth observations are used to narrowly restrict the first set of parameters. The parameters that affect one or more variables in the steady state a lot are $\mu, \theta, \sigma$, and 3 . In particular, as is evident from relations (1)-(4) above, there are close relationships between the parameter-variable combinations $\beta$ and $r$, $\sigma$ and $\mathrm{y}, \theta$ and $\mathrm{k}$ (and therefore $\mathrm{s}$ ), and $\mu$ and $\mathrm{h}$.

Some of the remaining parameters are determined from microstudies of firm and household behavior. The quarterly depreciation rate $\delta$ is set equal to 0.025 on the basis of microstudies. The resource allocation to new capital is assumed to be uniform over the construction period, and so all the $\phi_{i}$ 's are set equal to $1 / \mathrm{J}$. The value of $\mathrm{J}$ is set equal to three. This is one quarter less than what was assumed in Kydland and Prescott [1982]. Given that equipment and consumer durables are considered part of the capital stock, we think this represents better cali- 
bration as the construction periods for these durables are significantly less than a year.

Previous studies imply a narrow range of possible values for the curvature or risk-aversion parameter $\gamma$ in the utility function. We use -0.5 , which implies slightly more curvature than for the logarithmic utility function. In Kydland and Prescott [1982], the values $\alpha_{0}=0.5$ and $\eta=0.1$ were used and are used here. The selection of these values has recently received support from microstudies.

The parameter $v$, which determines to what elasticity of substitution between inventories and the composite capital-labor input, is not narrowly restricted. We did not find good measures of this parameter in the literature. Observations at the firm technology level, however, suggest limited substitution opportunities and consequently we restrict this parameter to be large. Admittedly, if good measurement found that this parameter is in fact smaller, the implications of theory would change some.

The parameter $\psi$, which determines to what extent the workweek is used as the margin over which to vary hours, is crucial to this model. Without variability in the workweek, this parameter is of course restricted to $1-\theta=0.64$. We have no good measure of this parameter for the U.S. economy, but clearly both margins are operative to a considerable extent. Thus, we chose the value of 0.82 , which is half way between the two extremes of 0.64 and one. ${ }^{2}$

The magnitude of the variance of the exogenous technology shocks and their serial correlation properties are measured by 
examining the statistical properties of changes in aggregate output not accounted for by changes in the inputs. The autoregressive coefficient $\rho$ in the law of motion for the permanent part of $z_{t}$ is fixed at 0.95 . The values for the standard deviations of the permanent, transitory, and indicator shocks, respectively, measured as percentages of the mean of $z_{t}$, are $0.0076,0.0015$, and 0.0076. The implied variance of the technology shock is approximately equal to that obtained by Prescott [1986] using Solow growth accounting to obtain a $z_{t}$ sequence. ${ }^{3}$ It is worth noting that permitting the workweek of capital to vary systematically with hours of employment affects hardly at all the estimate of the variance of the technology shock. Prescott [1986] finds that its value is reduced from 0.763 percent to only 0.759 percent when $\psi$ is increased from 0.64 to 0.85 . With $\psi=0.85$, the estimated standard deviation of the shock is at its smallest for any $\psi$.

We now return to the parameters determined by growth observations. With a quarterly real interest rate of one percent, a value for $\beta$ of 0.99 is implied. The average value for $h$ is 0.3 based upon the microfinding that households allocate about 30 percent of their productive time allocation to market production. ${ }^{4}$ The implied value of the parameter $\mu$ varies somewhat depending on model version. For the case of intertemporally nonseparable utility in leisure, for example, the value of $\mu$ is 0.325 when the production function parameter $\psi=1-\theta=0.64$, while its value becomes 0.274 in the example with $\psi=0.82$. The average inventory-output ratio is approximately one when output is measured quarterly. This yields a value of $\sigma$ of 0.01 . 
To determine capital's factor share, we added depreciation of capital to rental, corporate, and interest income. These national income account numbers were augmented by estimates of depreciation and implicit rental income on durables owned by the household. The results of these calculations for 1977, which is a typical year, was a factor share for capital of 36 percent. Besides implying $\theta=.36$, this share implies 10 for the quarterly capital-output ratio.

Computational Issues

Given the steady state, the remaining steps in the computation of equilibrium are similar to those described in Kydland and Prescott [1982]. To deal with nonlinearity in the resource constraint, we substitute for $c_{t}$ from the resource constraint in the utility function and then make a quadratic approximation around the model's rest point. As the remaining constraints are linear, it is then fairly straightforward to determine recursively the decision rules that describe the equilibrium behavior of the approximate economy. The decision variables are $h_{t}, s_{J t}, y_{t+1}$, and $c_{t}$, of which $c_{t}$ is determined from the resource constraint. The equilibrium can be represented by a linear stochastic system of difference equations consisting of constraints determining next period's capital stocks, the decision rules which are functions of a state vector that includes conditional expectations of the unobserved permanent and transitory technology shocks, and the linear relations for updating these conditional expectations from the most recent observations. ${ }^{5}$ 


\section{Findings}

Given a set of parameter values and variances of the three shocks, sample series can be generated from the model. These series are decomposed into a cyclical and a growth component using the same method as for the data. ${ }^{6}$ In joth cases, several statistics are computed and used for comparison. They are autocorrelations of output of order up to five, standard deviations of the cyclical components of all the variables, and their correlations with cyclical output. ${ }^{7}$ The U.S. statistics, using quarterly data, for the 116 quarter period 1954-82 are reported in Table 1. Using the model, 50 repeated samples of length 116 quarters are drawn, and averages and standard deviations are computed for each of the statistics.

We examine the statistical properties of the model economy and compare them with those of the post-war U.S. economy which are presented in Table 1. In particular, we want to know how much of the variability of real GNP and other key aggregate time series is accounted for by technological shocks whose magnitudes are of the same magnitude as the residuals of the aggregate production function. We also report statistics measuring comovements with the cycle, both contemporaneous and lead-lag relationships.

In Table 2, the statistics for the model economy with $\psi=0.64$, that is, with no variability in the workweek, are presented. This is the version of the current model which is close to the one in Kydland and Prescott [1982] with the main difference being the way in which inventories enter the production technol- 
ogy. With technology shocks calibrated to correspond to measured technology shocks, this economy accounts for roughly 80 percent of the variability of output. In Table 3 , the case of $\psi=0.82$ is presented. For it, the capital utilization rate varies directly with the labor utilization rate.

\section{The Major Finding}

Introducing a variable workweek of capital results in significantly larger output fluctuations in response to fluctuations in the Solow technology parameter. It is true that when the model economy with a variable workweek is calibrated, the variance of the technology shock is slightly smaller than for the economy without this feature. But, this is more than offset by the larger fluctuations induced by a shock of a given magnitude. The volatility measure of output is 1.79 for the calibrated variableworkweek economy while it is only 1.45 for the fixed-workweek economy. The value of the corresponding statistic for the postwar U.S. economy is 1.8 .

\section{Behavior of Inventories}

Inventory investment is a highly volatile component of output and contributes disproportionately to total output variability. In making comparisons between inventory statistics for the model and the U.S. economy it is important that inventories be measured in a similar way for the two economies. The U.S. data on inventories clearly include a significant portion of what in our model is physical capital under construction as our measure of capital includes consumer durables, such as automobiles, and 
equipment as well as structures. To measure inventories in a way closer to the actual data, some fraction of these goods in process should be added to inventories. We picked one-half, which implies in steady state that goods in process are one-eighth of all inventories.

With this definition of inventories, the effect of a variable workweek is to increase the volatility of inventories from 1.13 to 2.02 , which is even higher than the 1.7 figure for the U.S. data. Even though on average goods in process are only one-eight of total inventory stocks, this component matters a lot. Without this component, volatility of inventories for the model economy with a variable workweek would be only 0.67 rather than 2.02. It is important to note that our use of the expression goods in process does not correspond to reported goods in process. With reported statistics, finished goods of an independent auto part manufacturer are not included in goods in process while they are for parts divisions of auto manufacturers.

As can be seen from the tables, the cross-correlations between output and the inventory stock are much closer to the U.S. data for the variable-workweek economy than for the fixed-workweek economy. With the workweek variable inventory stocks like in the data lag output fluctuations.

\section{Hours Behavior}

Hours variability for the model is 1.12 which is substantially less than the 1.7 figure for the U.S. data. Another way to express this discrepancy is in terms of the output-labor elasticity emphasized by Lucas [1970], who estimated it to be near 
one. A puzzle at the time was the magnitude of the difference between this empirical elasticity and the one predicted by standard production-function specifications to equal labor's share. In our model, we can obtain the elasticity of cyclical output with respect to cyclical labor input by simply dividing the standard deviation of output by that of hours and multiplying by the correlation between hours and output. Doing that for each of the 116period samples from the model on which Table 3 is based gives us an average empirical elasticity of 1.52 with a standard deviation of 0.05 . This is of course much larger than the labor share, which illustrates the importance of technology shocks for our model.

In terms of the output-labor elasticity, we are faced with the opposite problem of Lucas, that is, we need to explain why the empirical elasticity for the U.S. is so low relative to the model. This issue is of course related to the above-mentioned discrepancy in hours variability. A possible explanation is measurement errors. Hansen's [1986] division of the population into six demographic groups according to age and sex indicates that actual cyclical hours should be multiplied by a factor of 0.94 in order to obtain hours in quality-adjusted units. In Kydland [1984], prime-age males were further divided into skill groups using years of education as the criterion. It was found that hours varied substantially more over the cycle for individuals with less education. Adding this element would reduce the variability of the quality-adjusted labor input significantly more. Furthermore, aggregate hours are difficult to measure 
accurately as evidenced by the discrepancy in figures obtained from establishment data and household data. ${ }^{8}$ The introduction of these factors reduces the empirical elasticity of output with respect to the labor input.

For example, if the cyclical variabilities of the quality-adjusted labor input is ninety percent of that of the unadjusted labor input and if there is an orthogonal error with standard deviation of 0.8 percent in measuring the labor input, ${ }^{9}$ the variability of hours is 1.47 and productivity 1.06 . The corresponding numbers for the U.S. post-war economy are 1.7 and 1.0 respectively. The contemporaneous correlation between productivity and GNP falls to 0.56 and the empirical output-labor elasticities becomes 0.98 .

Hours are somewhat more variable for the U.S. economy than for the calibrated model economy even when reasonable measurement errors are introduced. This discrepancy should not cast doubt upon our estimate of the contribution of technology shocks to aggregate fluctuations. There are surely other factors contributing to fluctuations such as terms-of-trade shocks, public finance shocks, preference shocks, and monetary shocks. All such sources of fluctuations, provided that their induced fluctuations are not strongly and positively correlated with those induced by the technology shocks, contribute to reducing the empirical laboroutput elasticity. That the empirical labor-output elasticity is so large is strong evidence in support of the finding that technology shocks are the primary source of aggregate fluctuations in the post-war U.S. economy. The fact that this elasticity is 
larger for the model economy than for the U.S. economy is evidence that other factors are of some importance.

\section{Other Findings}

One may wonder to what extent larger values of $\psi$ are a substitute for the intertemporally nonseparable utility function in terms of increasing the variability of hours and output and reducing the output-labor elasticity. For the economy with timeseparable preferences, that is $\alpha_{0}=1$, the finding is that as $\psi$ increases from 0.64 to 0.82 to 1.0 , the magnitude of output fluctuation increases from 1.30 percent to 1.46 percent to 1.68 percent when in fact it was 1.80 percent. Thus, the finding that fluctuations in response to technology shocks are larger if the workweek varies appears robust to the specification of preferences.

Imposing time-separable utility reduces output variability from 1.79 to 1.46 , with reductions of similar proportions in its components. Two variables for which the reduction in variability is particularly large are hours (to 0.67) and inventory stock (to 1.09). In the case of productivity, the variability rises to 0.85 , and the persistence of output movements is larger, with first and second-order autocorrelations of 0.72 and 0.46 .

With no time to build, the main differences are in the statistics for the capital stock. One change is a reduction in the variability of the capital stock in spite of a slight increase in the variability of output. Another change with time to build is that capital lags output to a greater extent and moves more in conformity with the data. A final important change is that the 
variability of the inventory stock is reduced from 2.02 to 0.57 . This occurs because there are no goods in process, the volatile component of the inventory stock.

VI. A Concluding Comment

Our analysis should not be interpreted to mean that fluctuations are optimal and that there is no role for stabilization policy. Our view is that public-finance considerations are not the principal factor driving the cycle and that abstracting from them at this stage is warranted. Only when we have considerable confidence in a theory of business cycle fluctuations would the application of public finance theory to the question of stabilization be warranted. ${ }^{10}$ Such an extension is straightforward in theory, though in all likelihood carrying it out will be difficult and will require ingenuity. 
Footnotes

*We thank Antonio Borges, Kevin Cotter, Rodolfo Manuelli, John Shoven, and Charles Whiteman for helpful comments, and the National Science Foundation and the Minneapolis Federal Reserve Bank for financial support.

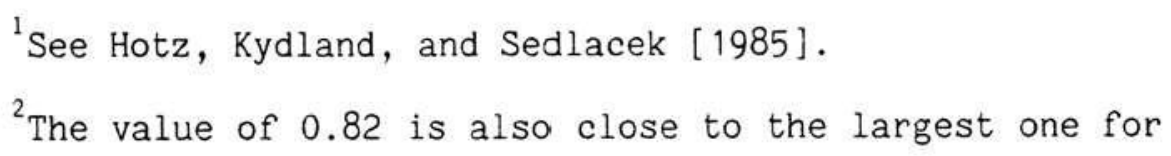
which our computational methods were applicable when the nonseparable utility function is used.

${ }^{3}$ Nelson and Plosser [1983, p. 153, footnote 15] report that a random walk process mimics well in a formal statistical sense the technology shocks that Solow [1957] obtains.

${ }^{4}$ For males, the figure is close to 40 percent. See Ghez and Becker [1975, page 95].

${ }^{5}$ Note that investment fluctuations are never large enough to make gross investment zero, so that it is not an issue whether to permit conversion of existing capital back to consumption goods.

${ }^{6}$ See Kydland and Prescott [1982, footnote 15].

${ }^{7}$ Available upon request are the complete set of statistics examined for the model economy and as well for studied variants of it. The appendix reports the economy's equilibrium set of stochastic difference equations.

${ }^{8}$ See Prescott [1986].

${ }^{9}$ This percentage is consistent with Prescott's [1986] findings. 
${ }^{10}$ See Shoven and Whalley [1984] for a review of applications of general equilibrium analysis to issues in public finance and trade. 
References

Debreu, G., 1954, Valuation equilibrium and Pareto optimum, Proceedings of the National Academy of Sciences 70, 588-92.

Ghez, G. R., and G. S. Becker, 1975, The allocation of time and goods over the life cycle (National Bureau of Economic Research, New York).

Hansen G., 1986, Fluctuations in total hours worked: a study using efficiency units, Chapter 3 of Three essays on labor indivisibilities and the business cycle (University of Minnesota Ph.D., Dissertation).

Hotz, V. J., F. E. Kydland and G. L. Sedlacek, 1985, Intertemporal preferences and labor supply, working paper (Carnegie-Mellon University, Pittsburgh, PA), forthcoming, Econometrica.

Jones, L. E., 1984, A competitive model of commodity differentation, Econometrica 52, 507-30.

Kuznets, S., 1966, Modern economic growth (Yale University Press, New Haven).

Kydland, F. E., 1983, Nonseparable utility and labor supply, presented at the NBER Conference on Macroeconomics, Cambridge (July), working paper (Hoover Institution, Stanford, CA). , 1984, Labor-force heterogeneity and the business cycle, Carnegie-Rochester Conference Series in Public Policy $21,173-208$.

Kydland, F. E. and E. C. Prescott, 1982, Time to build and aggregate fluctuations, Econometrica 50, 1345-70.

Lucas, R. E., Jr., 1970, Capacity, overtime and empirical production functions, American Economic Review 60, 23-27. 
Mas-Colell, A., 1975, A model of equilibrium with differentiated commodities, Journal of Mathematical Economics 2, 263-95.

Nelson, C. R. and C. I. Plosser, 1982, Trends and random walks in macroeconomic time series, Journal of Monetary Economics 10, $139-62$.

Prescott, E. C., 1983, Can the cycle be reconciled with a consistent theory of expectations? A progress report on business cycle theory, delivered at IMSSS Summer Workshop (Stanford University, Stanford, CA). , 1986, Theory ahead of business cycle measurement, Carnegie-Rochester Conference on Public Policy 25, 11-44.

Shoven, J. B. and J. Whalley, 1984, Applied general equilibrium models of taxation and international trade: An introduction and survey, Journal of Economic Literature 22, 1007-51.

Solow, R. M., 1957, Technical change and the aggregate production function, Review of Economics and Statistics 39, 312-20. 


\section{Appendix}

\section{Equilibrium Process For the Model}

Laws of Motion

$$
\begin{aligned}
& a_{t+1}=0.9 a_{t}+h_{t} \\
& k_{t+1}=0.975 k_{t}+s_{1 t} \\
& s_{1, t+1}=s_{2 t} \\
& s_{2, t+1}=s_{3 t} \\
& z_{1, t+1}=0.95 z_{1 t}+0.05917+\xi_{1, t+1} \\
& z_{2, t+1}=\xi_{2, t+1}, t+z_{2 t} \\
& z_{t}=z_{1 t}+z_{3 t} \\
& \pi_{t}=z_{t}+\xi_{2}
\end{aligned}
$$

Forecasting Rules

Let $\mathrm{m}_{0 t}$ be the expectation of $\left(z_{1 t}, z_{2 t}\right)^{\prime}$, conditionally on the previous history of $z_{\tau}, \tau<t$. Then the expectation of $\left(z_{1 t}, z_{2 t}\right)^{\prime}$, given $\pi_{t}$, is

$$
\mathrm{m}_{1 \mathrm{t}}=\left[\begin{array}{cc}
0.50129 & -0.49871 \\
-0.019659 & 0.98034
\end{array}\right] \mathrm{m}_{0 t}+\left[\begin{array}{l}
0.49871 \\
0.019659
\end{array}\right] \pi_{t} .
$$


The expectation of $\left(z_{1 t}, z_{2 t}\right)^{\prime}$, given $z_{t}$, is

$$
\mathrm{m}_{2 t}=\left[\begin{array}{cc}
0.037924 & -0.96208 \\
-0.037924 & 0.96208
\end{array}\right] \mathrm{m}_{1 t}+\left[\begin{array}{l}
0.96208 \\
0.037924
\end{array}\right] \mathrm{z}_{t} .
$$

Decision Rules

\begin{tabular}{cccc} 
State & \multicolumn{3}{c}{ Decision Variables } \\
Variables & $\mathrm{h}_{\mathrm{t}}$ & $\mathrm{s}_{\mathrm{Jt}}$ & $\mathrm{y}_{\mathrm{t}+1}$ \\
\hline $\mathrm{k}_{\mathrm{t}}$ & -0.0093319 & -0.25156 & 0.00050171 \\
$\mathrm{y}_{\mathrm{t}}$ & -0.0067304 & 2.2512 & 0.94847 \\
$\mathrm{a}_{\mathrm{t}}$ & -0.036587 & -0.18985 & -0.0059959 \\
$\mathrm{~s}_{1 \mathrm{t}}$ & -0.022726 & -1.1728 & -0.34657 \\
$\mathrm{~s}_{2 \mathrm{t}}$ & -0.010831 & -1.0872 & -0.33468 \\
const. $_{11 t}$ & 0.15672 & -1.4633 & -1.0833 \\
$\mathrm{~m}_{11 \mathrm{t}}$ & 0.30548 & 2.6288 & \\
$\mathrm{~m}_{12 \mathrm{t}}$ & 0.58741 & 5.3222 & \\
$\mathrm{~m}_{21 \mathrm{t}}$ & & & 0.57511 \\
$\mathrm{~m}_{22 \mathrm{t}}$ & & & 0.78731 \\
$\mathrm{~h}_{\mathrm{t}}$ & & & 2.3943 \\
$\mathrm{~s}_{\mathrm{Jt}}$ & & & -0.32354
\end{tabular}


Parameter Values

Preference

$$
\begin{aligned}
& \beta=0.990 \\
& \alpha_{0}=0.500 \\
& \eta=0.100 \\
& \mu=0.274 \\
& \gamma=-0.500
\end{aligned}
$$

\section{$\underline{\text { Technology }}$}

$$
\begin{array}{ll}
\psi=0.820 & \rho=0.950 \\
\theta=0.357 & \sigma=0.010 \\
J=3 & \nu=3.000 \\
\phi_{1}=0.333 & \delta=0.025 \\
\phi_{2}=0.333 & \\
\phi_{3}=0.333 &
\end{array}
$$

Covariance Matrix of Shocksa

$$
\Sigma_{\xi}=1.183^{2}\left[\begin{array}{ccc}
.00760^{2} & 0 & 0 \\
0 & .00154^{2} & 0 \\
0 & 0 & .00760^{2}
\end{array}\right]
$$

a/The 1.183 is the unconditional mean of the $z_{t}$ process. 
Table 1

Cyclical Behavior of the U.S. Economy

Deviations From Trend of Key Variables

$1954: 1-1982: 4$

Cross Correlation of Output With

Standard

Variables $\mathrm{x}$

Deviation $x(t-2) x(t-1) x(t) x(t+1) x(t+2)$

Gross National Product

$1.8 \%$

1.00

.82

.57

Personal Consumption Expenditures

Services

Nondurable Goods

.6
1.2

$\begin{array}{lllll}.53 & .66 & .72 & .61 & .52\end{array}$

Durable Goods

5.0

$.54 \quad .71$

$\begin{array}{lllll}.60 & .75 & .81 & .61 & .34\end{array}$

Fixed Investment Expenditures Nonresidential Investment Structures

Equipment

$\begin{array}{llllll}5.3 & .59 & .78 & .89 & .78 & .56 \\ 5.2 & .28 & .54 & .79 & .86 & .79 \\ 4.6 & .23 & .42 & .62 & .70 & .68 \\ 6.0 & .27 & .56 & .82 & .87 & .78\end{array}$

Capital Stocks

Total Nonfarm Inventories Nonresidential Structures Nonresidential Equipment

$\begin{array}{rrrrrr}1.7 & -.13 & .15 & .48 & .68 & .74 \\ .4 & -.36 & -.20 & -.03 & .16 & .32 \\ 1.0 & -.26 & -.03 & .23 & .41 & .54\end{array}$

Labor Input

Nonfarm Hours

1.7

.25

.57

.85

.89

.75

Productivity (GNP/Hours)

1.0

$.60 \quad .51$

$.34 \quad-.04 \quad-.28$

Source: Prescott [1983] who used the Citibank Data Base 
Table 2

Cyclical Behavior

of the Kydland-Prescott Economy

With Fixed Workweek*

\begin{tabular}{|c|c|c|c|c|c|c|}
\hline \multirow[b]{2}{*}{ Variables $\mathrm{x}$} & \multirow[b]{2}{*}{$\begin{array}{l}\text { Standard } \\
\text { Deviation }\end{array}$} & \multicolumn{5}{|c|}{ Cross Correlation of Output With } \\
\hline & & $x(t-2)$ & $x(t-1)$ & $x(t)$ & $x(t+1)$ & $x(t+2)$ \\
\hline Output & $\begin{array}{l}1.45 \% \\
(.16)\end{array}$ & $\begin{array}{l}.45 \\
(.09)\end{array}$ & $\begin{array}{l}.71 \\
(.06)\end{array}$ & $\begin{array}{l}1.00 \\
(--)\end{array}$ & $\begin{array}{l}.71 \\
(.06)\end{array}$ & $\begin{array}{l}.45 \\
(.09)\end{array}$ \\
\hline Consumption & $\begin{array}{l}.48 \\
(.06)\end{array}$ & $\begin{array}{l}.30 \\
(.08)\end{array}$ & $\begin{array}{l}.60 \\
(.05)\end{array}$ & $\begin{array}{l}.92 \\
(.02)\end{array}$ & $\begin{array}{l}.77 \\
(.05)\end{array}$ & $\begin{array}{l}.60 \\
(.09)\end{array}$ \\
\hline Investment & $\begin{array}{l}4.38 \\
(.46)\end{array}$ & $\begin{array}{l}.39 \\
(.10)\end{array}$ & $\begin{array}{l}.59 \\
(.08)\end{array}$ & $\begin{array}{l}.88 \\
(.03)\end{array}$ & $\begin{array}{l}.83 \\
(.02)\end{array}$ & $\begin{array}{l}.51 \\
(.07)\end{array}$ \\
\hline Inventory Stock & $\begin{array}{l}1.13 \\
(.09)\end{array}$ & $\begin{array}{l}.31 \\
(.09)\end{array}$ & $\begin{array}{l}.50 \\
(.08)\end{array}$ & $\begin{array}{l}.79 \\
(.04)\end{array}$ & $\begin{array}{l}.67 \\
(.05)\end{array}$ & $\begin{array}{l}.22 \\
(.11)\end{array}$ \\
\hline Capital Stock & $\begin{array}{l}.40 \\
(.06)\end{array}$ & $\begin{array}{l}-.34 \\
(.10)\end{array}$ & $\begin{array}{l}-.21 \\
(.08)\end{array}$ & $\begin{array}{l}-.07 \\
(.07)\end{array}$ & $\begin{array}{l}.17 \\
(.04)\end{array}$ & $\begin{array}{l}.53 \\
(.03)\end{array}$ \\
\hline Hours & $\begin{array}{l}.86 \\
(.09)\end{array}$ & $\begin{array}{l}.42 \\
(.10)\end{array}$ & $\begin{array}{l}.63 \\
(.07)\end{array}$ & $\begin{array}{l}.93 \\
(.01)\end{array}$ & $\begin{array}{l}.69 \\
(.04)\end{array}$ & $\begin{array}{l}.38 \\
(.08)\end{array}$ \\
\hline $\begin{array}{l}\text { Productivity } \\
\text { (Output/Hours) }\end{array}$ & $\begin{array}{l}.72 \\
(.06)\end{array}$ & $\begin{array}{l}.38 \\
(.08)\end{array}$ & $\begin{array}{l}.68 \\
(.05)\end{array}$ & $\begin{array}{l}.90 \\
(.02)\end{array}$ & $\begin{array}{l}.60 \\
(.08)\end{array}$ & $\begin{array}{l}.45 \\
(.10)\end{array}$ \\
\hline $\begin{array}{l}\text { Real Interest Rate } \\
\text { (Annual) }\end{array}$ & $\begin{array}{l}.17 \\
(.02)\end{array}$ & $\begin{array}{l}.47 \\
(.10)\end{array}$ & $\begin{array}{l}.69 \\
(.07)\end{array}$ & $\begin{array}{l}.85 \\
(.09)\end{array}$ & $\begin{array}{l}.58 \\
(.12)\end{array}$ & $\begin{array}{l}.42 \\
(.08)\end{array}$ \\
\hline
\end{tabular}

*These are the means of 50 simulations, each of which was 116 periods long. The numbers in parentheses are standard errors. 
Table 3

Cyclical Behavior of the

Modified Kydland-Prescott Economy

With Variable Workweek*

Cross Correlation of Output With

\begin{tabular}{|c|c|c|c|c|c|c|}
\hline Variables $\mathrm{x}$ & $\begin{array}{l}\text { Standard } \\
\text { Deviation }\end{array}$ & $x(t-2)$ & $x(t-1)$ & $x(t)$ & $x(t+1)$ & $x(t+2)$ \\
\hline Output & $\begin{array}{l}1.79 \% \\
(.19)\end{array}$ & $\begin{array}{l}.39 \\
(.10)\end{array}$ & $\begin{array}{l}.65 \\
(.07)\end{array}$ & $\begin{array}{l}1.00 \\
(--)\end{array}$ & $\begin{array}{l}0.65 \\
(.07)\end{array}$ & $\begin{array}{l}.39 \\
(.10)\end{array}$ \\
\hline Consumption & $\begin{array}{l}.56 \\
(.07)\end{array}$ & $\begin{array}{l}.26 \\
(.08)\end{array}$ & $\begin{array}{l}.57 \\
(.05)\end{array}$ & $\begin{array}{l}.90 \\
(.03)\end{array}$ & $\begin{array}{l}.74 \\
(.06)\end{array}$ & $\begin{array}{l}.59 \\
(.09)\end{array}$ \\
\hline Investment & $\begin{array}{l}5.27 \\
(.56)\end{array}$ & $\begin{array}{l}.41 \\
(.10)\end{array}$ & $\begin{array}{l}.57 \\
(.08)\end{array}$ & $\begin{array}{l}.89 \\
(.03)\end{array}$ & $\begin{array}{l}.80 \\
(.03)\end{array}$ & $\begin{array}{l}.43 \\
(.08)\end{array}$ \\
\hline Inventory Stock & $\begin{array}{l}2.02 \\
(.34)\end{array}$ & $\begin{array}{l}.25 \\
(.06)\end{array}$ & $\begin{array}{l}.18 \\
(.14)\end{array}$ & $\begin{array}{l}.60 \\
(.08)\end{array}$ & $\begin{array}{l}.52 \\
(.05)\end{array}$ & $\begin{array}{l}.00 \\
(.13)\end{array}$ \\
\hline Capital Stock & $\begin{array}{l}.57 \\
(.08)\end{array}$ & $\begin{array}{l}-.33 \\
(.08)\end{array}$ & $\begin{array}{l}-.06 \\
(.10)\end{array}$ & $\begin{array}{l}-.10 \\
(.06)\end{array}$ & $\begin{array}{l}.08 \\
(.07)\end{array}$ & $\begin{array}{l}.56 \\
(.03)\end{array}$ \\
\hline Hours & $\begin{array}{l}1.12 \\
(.12)\end{array}$ & $\begin{array}{l}.36 \\
(.11)\end{array}$ & $\begin{array}{l}.56 \\
(.09)\end{array}$ & $\begin{array}{l}.95 \\
(.01)\end{array}$ & $\begin{array}{l}.59 \\
(.07)\end{array}$ & $\begin{array}{l}.29 \\
(.09)\end{array}$ \\
\hline $\begin{array}{l}\text { Productivity } \\
\text { (Output/Hours) }\end{array}$ & $\begin{array}{l}.81 \\
(.07)\end{array}$ & $\begin{array}{l}.35 \\
(.09)\end{array}$ & $\begin{array}{l}.66 \\
(.05)\end{array}$ & $\begin{array}{l}.90 \\
(.02)\end{array}$ & $\begin{array}{l}.62 \\
(.08)\end{array}$ & $\begin{array}{l}.46 \\
(.10)\end{array}$ \\
\hline $\begin{array}{l}\text { Real Interest Rate } \\
\text { (Annual) }\end{array}$ & $\begin{array}{l}.25 \\
(.05)\end{array}$ & $\begin{array}{l}.38 \\
(.11)\end{array}$ & $\begin{array}{l}.64 \\
(.09)\end{array}$ & $\begin{array}{l}.64 \\
(.20)\end{array}$ & $\begin{array}{l}.43 \\
(.16)\end{array}$ & $\begin{array}{l}.36 \\
(.08)\end{array}$ \\
\hline
\end{tabular}

* These are the means of 50 simulations, each of which was 116 periods long. The numbers in parentheses are standard errors. 